\title{
Investigation into the dissimilar friction stir welding of AA7020-T651 and AA6060-T6
}

\author{
Landry Giraud ${ }^{\mathrm{a}, \mathrm{b}}$, Hugo Robe ${ }^{\mathrm{a}, \mathrm{b}, *}$, Christophe Claudin ${ }^{\mathrm{a}}$, \\ Christophe Desrayaud ${ }^{\mathrm{c}}$, Philippe Bocher ${ }^{\mathrm{d}}$, Eric Feulvarch ${ }^{\mathrm{a}}$ \\ ${ }^{a}$ Univ Lyon, ENISE, LTDS UMR 5513 CNRS, 58 rue Jean Parot, 42023 Saint-Étienne \\ cedex 02, France \\ ${ }^{b}$ TRA-C industrie, ZAC des Olmes, 69490 Les Olmes, France \\ ${ }^{c}$ Ecole des Mines de Saint Etienne, LGF UMR 5307 CNRS, 158 Cours Fauriel, 42023 \\ Saint-Étienne, France \\ ${ }^{d}$ Mechanical Engineering Department, École de Technologie Supérieure (ÉTS), 1100 \\ Rue Notre-Dame Ouest, Montréal H3C 1K3, Québec, Canada
}

\begin{abstract}
In this present paper friction stir welding of dissimilar heat treatable aluminium alloys 7020-T651 and 6060-T6 has been studied. An experimental analysis is presented based on results obtained from temperatures and efforts measurements in a range of advance speed from $300 \mathrm{~mm} . \mathrm{min}^{-1}$ to $1100 \mathrm{~mm} \cdot \mathrm{min}^{-1}$ and rotation speed from $1000 \mathrm{rev} \cdot \mathrm{min}^{-1}$ to $2000 \mathrm{rev} \cdot \mathrm{min}^{-1}$. Dissimilar welding does not seem to induce a hotter side but efforts are very sensitive to process parameters. The material mixing of dissimilar configurations has been investigated by means of macro and microstructural observations and has revealed the complex mechanisms of material flow into the nugget. The as-welded mechanical behaviour has been characterized using quasi-static tensile tests. The cross-weld microhardness has
\end{abstract}

*. Corresponding author.

Email addresses: 1.giraud@tra-c.com (Landry Giraud), h.robe@tra-c.com (Hugo Robe), eric.feulvarch@enise.fr (Eric Feulvarch)

Preprint submitted to Journal of Materials Processing Technology

April 12, 2016 
also been studied for various operating parameters. Computed maps correlated the microstructural features helping us establish weak zones. All these characterizations make it possible to determine a large window of industrial parameters capable of welding properly two $5 \mathrm{~mm}$ sheets of AA7020-T651 and AA6060-T6 with good mechanical properties.

Keywords: friction stir welding, dissimilar welding, aluminium alloys

\section{Introduction}

Friction Stir Welding (FSW) is a joining process performed in solid state. It was developed and patented by Thomas et al. (1995) with The Welding Institute (TWI). At the beginning, the process was mainly used for joining aluminium alloys and light materials. However many developments relating to the FSW of high melting point materials are currently underway to extend the applications of this process. In FSW, heat is generated from both the stirring of the base materials and its friction with a non-consumable tool.

Microstructural changes during welding were studied by Zhao et al. (2010) and permitted to demonstrate the difference between fusion welding and FSW. As explained by Genevois et al. (2005) the solid-state largely prevents solidification problems like hot tearing and porosity. Carlone and Palazzo (2015) have furthermore revealed that residual stresses and distortions are minor. Therefore, the strength of aluminium FSW joints often exceeds by more than $20 \%$ that of fusion welding joints. Muñoz et al. (2008) have investigated the mechanical behaviour of Al-Mg-Sc of both TIG and FSW joints and highlighted a reduction of $30 \%$ in the yield stress for fu- 
sion welds explained by a complete dissolution of $\mathrm{Al}_{3} \mathrm{Sc}$ hardening particles. FSW doesn't require any filler metal whose choice is crucial for the weld quality (Feulvarch et al. (2011)).

Due to these advantages, FSW is more and more widely used in many fields of industry, all the more so as it can join dissimilar alloys. For conventional welding processes, the difference in thermal conductivity is one of the main problems as explained by Luijendijk (2000), which leads to avoiding this configuration whenever possible. In the literature, a number of studies, like Mubiayi and Akinlabi (2013) paper, depict the proceedings and difficulties of dissimilar joining. As demonstrated in Cavaliere et al. (2009) and Jonckheere et al. (2013) works, the choice of the material placement is a great issue. Murr (2010) has studied various dissimilar welding combinations such as aluminium alloys AA6061 and cast aluminium A339 and exhibited the complex behaviour of each material combination as well. During the welding of heat-treatable alloys with strain hardening alloys Dilip et al. (2010) and Ilangovan et al. (2015) have reported strong effect on hardness variation through the joint and therefore on the mechanical behavior with a non-homogeneous stress distribution. In their dissimilar study of AA5052-H32 / 6061-T6, Park et al. (2010) have shown that annealing phenomena in the side of AA5052 induces a microhardness minimum which is also the privileged area for fracture. FSW also allows the challenge of joining noteworthy dissimilar assemblies as $\mathrm{Al} / \mathrm{Mg}$ Khodir and Shibayanagi (2007)] or $\mathrm{Al} / \mathrm{Cu}$ [Carlone et al. (2015)]. The major difficulty is in the control of the formation of intermetallic compounds (IMCs) in the interface between both materials. IMCs could lead to a greater mechanical weakness because of their brittle nature. The properties can be improved by 
restricting the heat generation with cooling system like submerged friction stir welding as reported by Mofid et al. (2014).

In this study, the butt joint welding of 2 precipitation hardening alloys AA7020-T651 and AA6060-T6 is investigated. The whole study takes place in a strong industrial context, i.e. the welding parameters are high compared to those published in the literature. In FSW, material mixing is not well understood in case of heterogeneous welding, especially when it is necessary to link and confront it to the welding parameters. This is what we propose to highlight in this work. AA7020-T651 is an Al-Zn-Mg alloy commonly used in the defence industry due to its high mechanical properties and AA6060T6 is an Al-Mg-Si alloy well known for its formability and application in the automotive industry. Both alloys belong to structural hardening aluminium.

One typical evidence of local heterogeneities in FSW structures is the presence of onion-rings. Onion-rings are well known FSW features and are considered as cross-section of the banded structure. Tongne et al. (2015) and Gratecap et al. (2012) explained the formation of these features by periodical layer deposition behind the pin. The widely documented AA2024 / AA7075 dissimilar welding has been studied by da Silva et al. (2011) and correlated the formation of onion-rings to the high rotational speed. $\mathrm{Xu}$ and Deng (2008) have confirmed these assumptions with various welding parameters. Izadi et al. (2013) have shown that the formation of onionrings in dissimilar welding is due to the presence of thread on the tool profile which promotes the intermixing of both materials and can be increased by a low travel speed. Moreover, to increase the stirring of the initial interface, a good design of the welding tool is required. Besides, a " $\mathrm{S}$ " shape which is the deformed initial interface of the joined parts can be found where onion- 
rings are absent in the thickness as demonstrated by $\mathrm{Xu}$ and Deng (2008). Dilip et al. (2010) showed that the weld strength is not significantly affected by this kind of shape.

Several authors have studied and tried to explain the material flow during FSW using various technical solutions: Lorrain et al. (2010) with markers along the weld line, the stop-action technique in da Silva et al. (2011) work, Robe et al. (2015) have made microstructure analyses in a few directions, and numerical simulations were performed by Tongne et al. (2015), Hamilton et al. (2008), and Nandan et al. (2006)). Some controversies on the mechanisms involved still remain. It was observed that in FSW, the weld is formed mostly by Advancing Side (AS) material because it is the one close to the tool and then, the material mostly dragged to the weld seam. Therefore, the hardest material is often placed in the AS in order to increase the weld hardness as reported by Dilip et al. (2010). Only based on the literature, it is difficult to conclude about the optimal material position for dissimilar welding. The positioning and mixing abilities appear to be highly materials and process parameters dependent.

In this present paper the dissimilar friction stir welding of AA7020-T651 and AA6060-T6 has been investigated. At first, the welding processing and the characterisation procedures are detailed. Then, an experimental analysis is presented based on results obtained from temperatures and efforts measurements in a range of advance speed from $300 \mathrm{~mm} \cdot \mathrm{min}^{-1}$ to 1100 mm. $\mathrm{min}^{-1}$ and rotation speed from $1000 \mathrm{rev} \cdot \mathrm{min}^{-1}$ to $2000 \mathrm{rev} \cdot \mathrm{min}^{-1}$. The mixing of dissimilar configurations has been investigated by means of macro and microstructural observations. The mechanical behaviour has been characterized using quasi-static tensile tests and the microhardness through the 
joint has also been studied for various operating parameters.

\section{Materials and Methods}

Friction stir welded samples are made with 300x150 mm butt joined sheets of AA7020-T651 and AA6060-T6 in 5 mm thick. Heat treatment T6 is composed of solutionizing, quenching, and artificial ageing while T651 treatment added controlled traction between the quenching and ageing steps. The nominal composition (in weight percent) of each material is given in Table 1. The choice has been made to place the stronger material (AA7020-T651) on AS according to da Silva et al. (2011) and Dilip et al. (2010) works. AA7020-T651 rolling direction and AA6060-T6 extrusion direction are $90^{\circ}$ shifted, in such a way that the extrusion direction is parallel to the welding direction. This configuration is shown in Fig. 1. In this paper, the welding direction will be referred to as WD and cross-weld direction as $\mathrm{CW}$, to avoid confusion with base material directions.

\begin{tabular}{lccccccccc}
\hline Alloy & $\mathrm{Zn}$ & $\mathrm{Mg}$ & $\mathrm{Fe}$ & $\mathrm{Si}$ & $\mathrm{Cu}$ & $\mathrm{Cr}$ & $\mathrm{Mn}$ & $\mathrm{Ti}$ & $\mathrm{Al}$ \\
\hline 7020-T651 & $4.0-5.0$ & $1.0-1.4$ & 0.40 & 0.35 & 0.2 & $0.10-0.35$ & $0.05-0.5$ & - & Bal. \\
6060-T6 & $\max 0.13$ & $0.35-0.6$ & $0.1-0.5$ & $0.3-0.6$ & $\max 0.1$ & $\max 0.05$ & 0.1 & 0.1 & Bal. \\
\hline
\end{tabular}

Table 1: Chemical composition of 7020-T651 and 6060-T6 aluminium alloys in wt\%.

All friction stir welds were performed by TRA-C industrie on a CFSW (China Friction Stir Welding Center) LM-B FSW machine with a threaded tool. The tool geometry includes a $15 \mathrm{~mm}$ diameter scrolled shoulder with a tapered, threaded Triflat ${ }^{T M} 4.8 \mathrm{~mm}$ long probe as illustrated in Fig.2, Every test was repeated several times (at least twice) to confirm the repeatability 


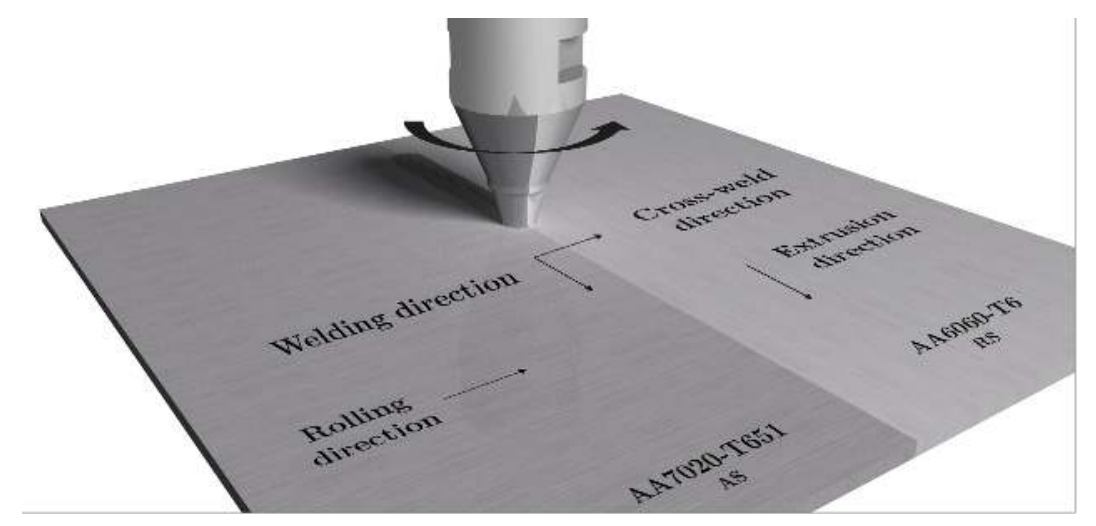

Figure 1: Experimental dissimilar FSW set up.

of the welding. The process parameters and samples names are reported in Table 2. As one can see, the ratio between the advance and rotational speed $R$ ratio was evaluated to classify the different welds. $R$ is the ratio between the advance and rotational speed. Regarding the amount of energy locally given to the sheets, a high $\mathrm{R}$ ratio is considered as cold joining and a small $\mathrm{R}$ ratio as hot joining.

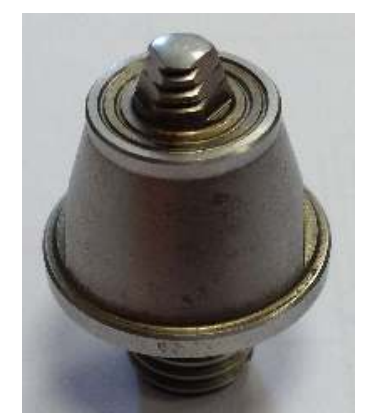

Figure 2: Triflat FSW tool used for the welding trials.

For each experiment, thermal cycles and welding efforts have been measured. The temperatures were measured with 16 K-type thermocouples 


\begin{tabular}{lccc}
\hline Samples & Advance speed $\left(\mathrm{mm} \cdot \mathrm{min}^{-1}\right)$ & Rotation speed $\left(\mathrm{rev} \cdot \mathrm{min}^{-1}\right)$ & $\mathrm{R} \mathrm{ratio}\left(\mathrm{mm} \cdot \mathrm{rev}^{-1}\right)$ \\
\hline BW1 & 300 & 1000 & 0.3 \\
BW2 & 700 & 1000 & 0.7 \\
BW3 & 1100 & 1000 & 1.1 \\
BW4 & 300 & 1500 & 0.2 \\
BW5 & 700 & 1500 & 0.47 \\
BW6 & 1100 & 1500 & 0.73 \\
BW7 & 300 & 2000 & 0.15 \\
BW8 & 700 & 2000 & 0.35 \\
BW9 & 1100 & 2000 & 0.55 \\
\hline
\end{tabular}

Table 2: Welding parameters and samples names.

flooded into the workpiece at $2.5 \mathrm{~mm}$ (mid-thickness) and at a different distance from the weld line (see Fig. 3a). The thermocouples holes were filled with thermogrease as we can see on Figure 3b. Efforts acquisition was performed with a $60 \mathrm{kN}$ Kistler 3-components piezzoelectric load-cell.

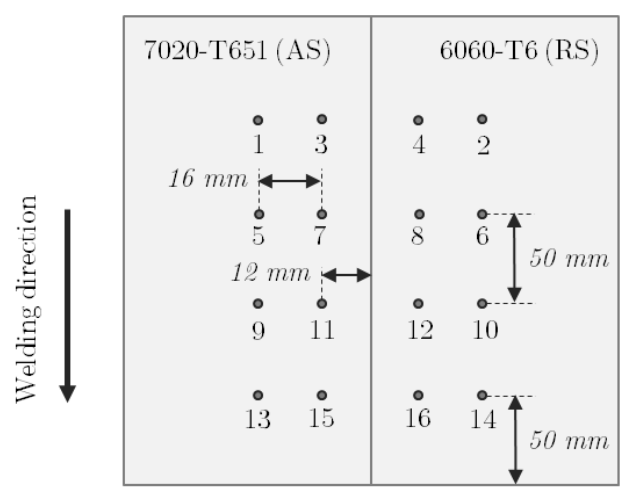

(a)

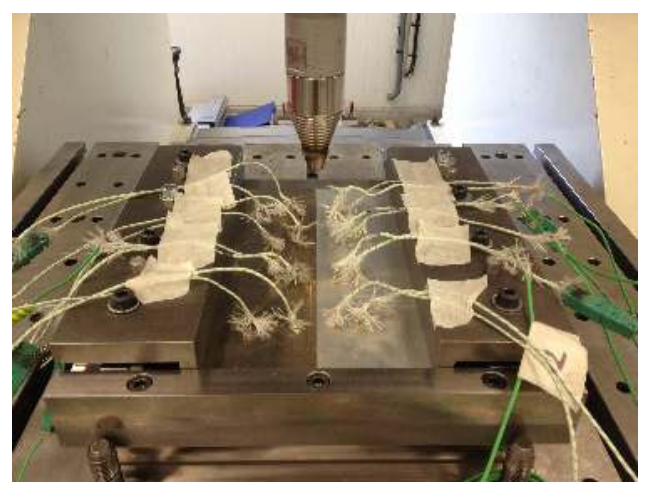

(b)

Figure 3: : (a) Thermocouples position and (b) experimental temperature and forces measurement set up. 
To achieve the macrographs, a standard polishing procedure was performed. All the welds were etched by means of a Keller etchant (2 ml HF $+3 \mathrm{ml} \mathrm{HCl}+5 \mathrm{ml} \mathrm{HNO} 3+190 \mathrm{ml} \mathrm{H} 2 \mathrm{O}$ ) for $30 \mathrm{~s}$. Then the observation was made with a binocular microscope. For the micrographs, an anodic oxidation was performed in order to reveal all the microstructure features.

Tensile test were performed 3 times for each welding parameters at room temperature on a $600 \mathrm{kN}$ Zwick machine at a rate of $2 \mathrm{~mm} \cdot \mathrm{min}^{-1}$. The welded samples were taken along the cross-weld (CW) direction. Tests were also performed in both main directions for base materials: rolling direction (or extrusion direction) and transverse direction. Fig. 4 shows the tensile specimens geometry (following ASTM-E8 standard). For the 9 trials the samples were collected in a part of the weld where a steady state condition is assumed. During the tensile test, the elongation was recorded with an extensometer with a gauge length of $45 \mathrm{~mm}$.

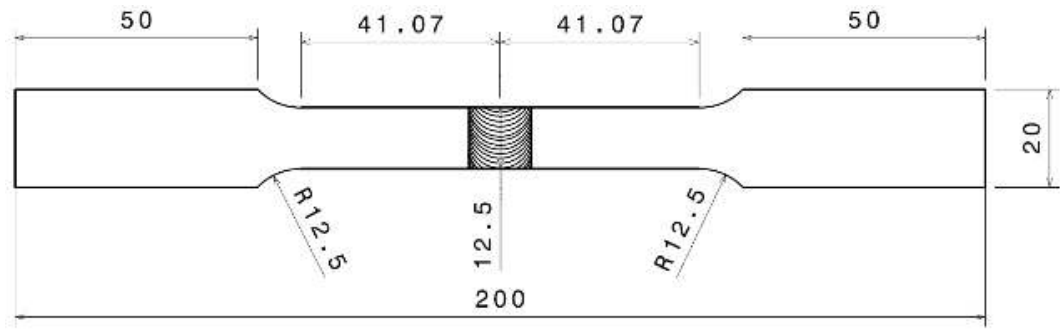

Figure 4: Tensile samples geometry (thanks to ASTM-E8 standard).

The Vickers microhardness tests have been performed with a Buehler automatic machine and an optical microscope under a load of $100 \mathrm{gf}$ (microhardness HV0.1). Maps were then numerically computed by means of around 400 points indents (depending on the sample length), i.e. the resolution on the $\mathrm{X}$ direction was $0.74 \mathrm{~mm}$ and $0.44 \mathrm{~mm}$ on the $\mathrm{Y}$ direction. 


\section{Results and Discussion}

\subsection{Instrumented test}

Even if the dissimilar metals have significant differences in their thermal properties (Thermal conductivity: $140 \mathrm{~W} \cdot \mathrm{m}^{-1} \cdot \mathrm{K}^{-1}$ for AA7020-T6 and $209 \mathrm{~W} \cdot \mathrm{m}^{-1} \cdot \mathrm{K}^{-1}$ for AA6060-T6), not major differences were found between both sides of the joint (Table 3). Many works dealing with temperature measurements reported that a small difference between AS and RS is always present in similar or dissimilar FSW Mofid et al. (2014) due to the difference in material velocity from one side to the other. Considering the distance of thermocouples from the weld line and that steel fixtures were used, the difference in the specific heat capacity or thermal pumping is the main phenomenon which may be the source of no real difference in temperatures. As expected, a higher rotational speed induces a higher maximum temperature in the weld while an increase in the feed rate results in a reduction of the maximum temperature field.

Fig. 5 exhibits the typical variation of Z-force with time. The time can be divided according to the tool position in order to highlight the different welding steps (plunging, dwell time, welding, and retracting). The graph can also explain the peaks and force variation during the plunging step. The first peak represents the force generated by the contact between the sheet and the pin, which is then stabilized during the plunging stage. The shoulder contact increases again the force followed by a force reduction with the thermal softening of the area around the tool during the $5 \mathrm{~s}$ dwell step. The second graph of Fig. 5 shows the thermal stability reached during the welding step along the X-axis on AS (4 thermocouples along the weld). The range of peak temperature variations is about $10^{\circ} \mathrm{C}$. Each peak is positioned 


\begin{tabular}{|c|c|c|c|c|c|c|}
\hline \multirow[b]{3}{*}{ Advance speed $\left(\mathrm{mm} \mathrm{min}^{-1}\right)$} & \multicolumn{6}{|c|}{ Rotation speed (mm.rev ${ }^{-1}$ ) } \\
\hline & \multicolumn{3}{|c|}{ Advancing side } & \multicolumn{3}{|c|}{ Retreating side } \\
\hline & 1000 & 1500 & 2000 & 1000 & 1500 & 2000 \\
\hline \multicolumn{7}{|c|}{ Distance from weld center line : $12 \mathrm{~mm}$} \\
\hline 300 & 243 & 267 & 287 & 242 & 266 & 273 \\
\hline 700 & 188 & 224 & 238 & 184 & 211 & 237 \\
\hline 1100 & 149 & 169 & 177 & 164 & 153 & 170 \\
\hline \multicolumn{7}{|c|}{ Distance from weld center line : $28 \mathrm{~mm}$} \\
\hline 300 & 120 & 151 & 138 & 118 & 113 & 150 \\
\hline 700 & 101 & 109 & 116 & 110 & 115 & 120 \\
\hline 1100 & 91 & 104 & 101 & 111 & 109 & 113 \\
\hline
\end{tabular}

Table 3: Average maximum temperatures $\left({ }^{\circ} \mathrm{C}\right)$ measured during welding at different parameters and positions.

according to its $\mathrm{X}$-axis position from the beginning $\left(\mathrm{X}_{d}\right)$ to the end $\left(\mathrm{X}_{f}\right)$ of the weld. Points $\mathrm{X}_{1}$ to $\mathrm{X}_{4}$ correspond to the thermocouple lines shown in Fig. 3a.

\subsection{Microstructural analysis}

\subsubsection{Microstructure}

The optical micrographs of both base materials are shown in Fig. 6 , revealing the grain structure after etching. The AA7020-T651 alloy was hot rolled and exhibits a classic elongated grains microstructure (see Fig. 6a), created by the severe deformation during the transformation. Actually, even if dynamic recovery occurred during the rolling operation, the grain boundaries followed the elongation of the bulk material, but no boundary 11 

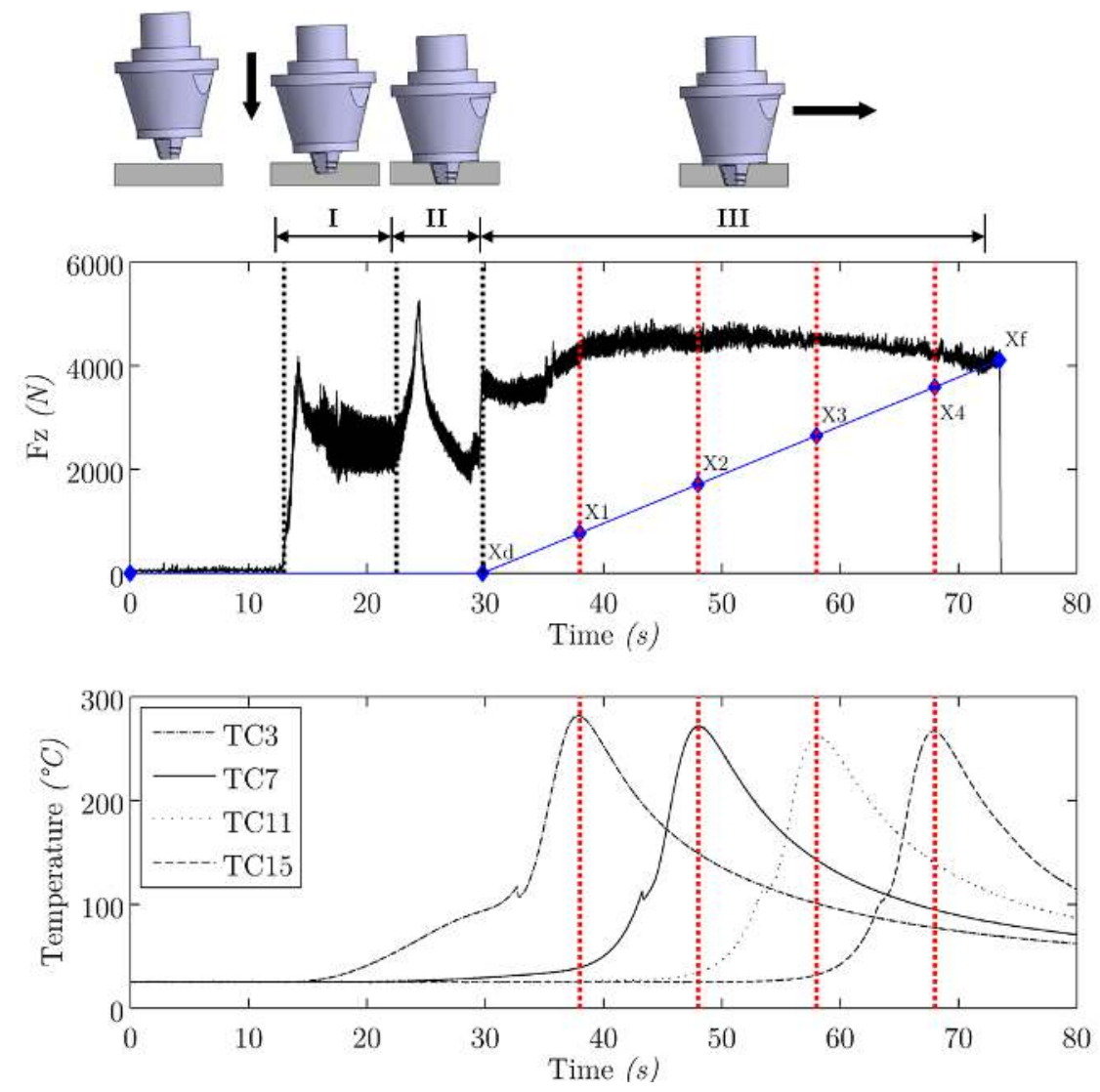

Figure 5: Z-force variation along the weld line: I-Plunge stage, II-Shoulder contact and dwell time (5 s), III-Translation stage. Peak temperatures measured by thermocouples during welding.

migration is observed in the AA7020 certainly due to the Zener pining and solute drag effects. On the contrary, the 6060 aluminium alloy exhibits a recrystallized microstructure (see Fig. 6b) certainly due to the homogenization set operated to reach the T6 state after the extrusion process. Indeed these alloys are known to recrystallize at high temperature and especially during the solutionizing operation.

As one can see on Fig. 7, all CW-macrographs are shown on a plot where 


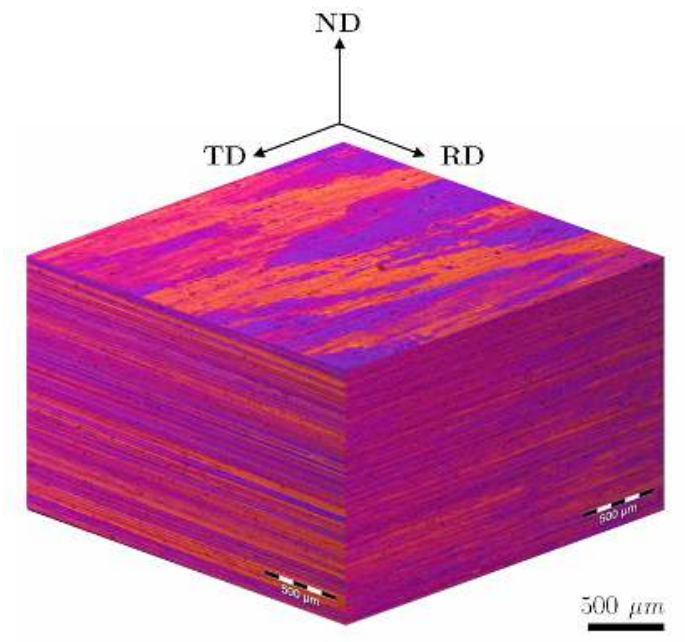

(a)

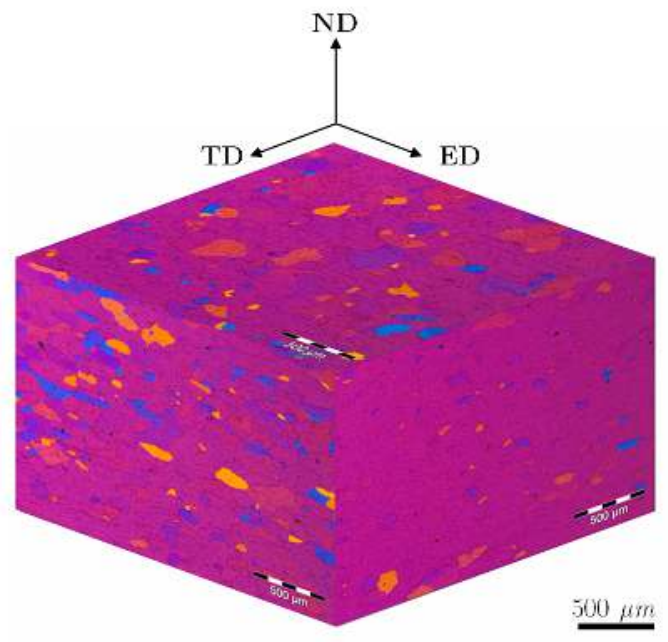

(b)

Figure 6: Pseudo-3D optical micrographs of base metals for: (a) AA7020-T651 and (b) AA6060-T6.

the welding conditions are also represented. All welds revealed more particularly the effect of the process parameters on the grain structure formation (strain, grain size evolution...). As expected with previous observations on base metals, both can be easily identified by means of their colour, grain size, shape, and reaction to chemical etching. Indeed AA6060-T6 is darker and less etched than AA7020-T651 which reveals its "pancakes" grains and seam zones. One can note that only 2 welds out of 9 have some voids highlighted with red circle. For the BW3 a tunnel defect is observed due to the low temperatures recorded (Table 3) and clearly expected considering the operating conditions: low rotative and high motion velocities. The voids observed in the BW1 are far less significant and maybe due to local flow incompatibility. 


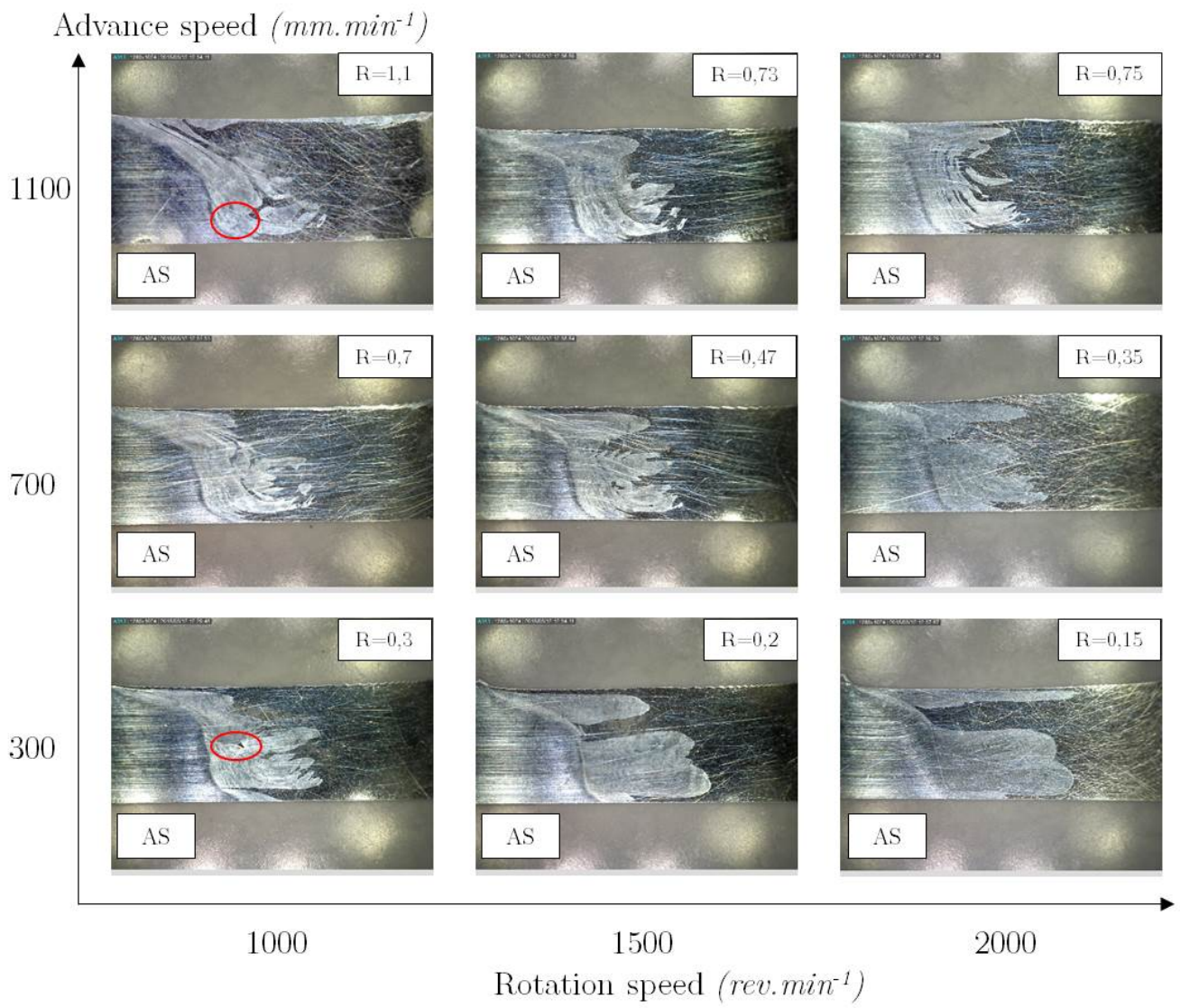

Figure 7: Optical cross-weld macrographs matrix.

It is interesting to notice that the shapes of the two materials are different, varying with the process parameters. On several pictures, it is possible to distinguish the formation of onion-rings . The shape of the joint varies with the $\mathrm{R}$ ratio: it seems that for a small $\mathrm{R}$ ratio (i.e cold weld), there is an "S" shape, with flow arm formation, and when R increases (i.e hot weld), the shape becomes more and more chaotic with the formation of onions-rings. To prove the stability of the process and regularity of materials mixing, the 4 lines displayed in Fig. 8 represent the interface evolution for 4 welds, all 
welded for BW7 condition (2000 rev. $\mathrm{min}^{-1}$, $300 \mathrm{~mm} \cdot \mathrm{min}^{-1}$ ). One can see the regular evolution of the interface between each materials into the nugget (the repeatability of the other configurations is not shown in this paper for brevity).

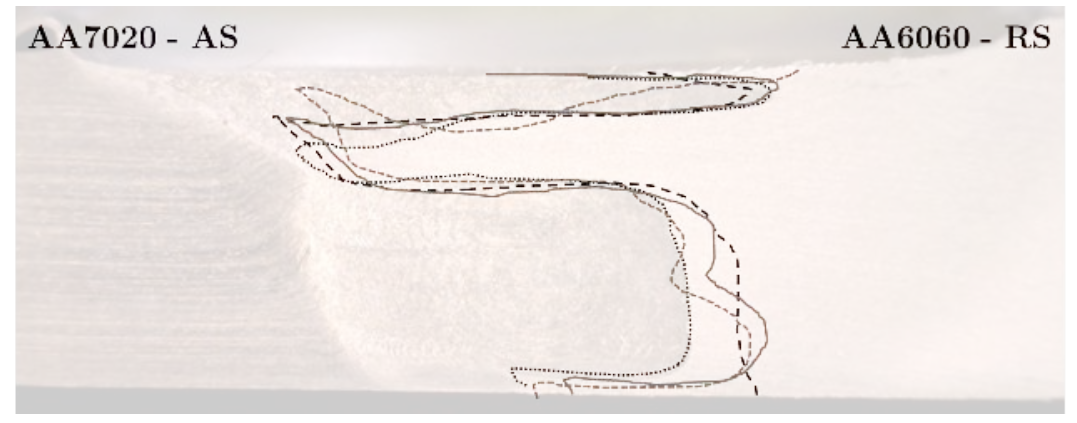

Figure 8: Interfaces repeatability (4 times) for BW7 condition.

The grains are highly affected by strain which induce large deformations in HAZ and TMAZ. This point can be partially controlled by the heat input, hence by the $\mathrm{R}$ ratio. The various macrographs seems to reveal that the more chaotic the interface is (high $\mathrm{R}$ ratio), the less deformed the 7020-T651 in TMAZ grains are. Even if the grains are less deformed, the transition between the base material and recrystallized material in the nugget is sharper when $\mathrm{R}$ ratio increases. The nugget borders are nearly vertical for the warmer conditions contrary to the "low temperature" conditions where the width of the welded zones is much smaller in the depth of the metal sheet.

Grain size examination was done on the nugget zone of the weld. This region exhibits the most severe grain evolution as various mechanisms, such as recovery and recrystallization, are active at the temperatures and strain rates reached by the material in this location of the joint. Measurements 
were only done at AA6060 side because of the very small grain size of AA7020 side inside the nugget. A wide area of the joint was scanned with a corresponding number of measured grains between 100 and 150. A good statistical accuracy was reached to determine the average grain size with small standard deviation for the whole representative region: from 2 to 9 $\mu \mathrm{m}$. All the information is summed up in Table 4 with an ascending classification based on the value of the $\mathrm{R}$ ratio. The extreme conditions (BW7, BW4, BW6, and BW3) allow the following conclusion to be drawn: cold conditions (low welding speed) enhanced grain refinement. According to Gourdet and Montheillet (2003), the dynamic recrystallization mechanisms govern the grain size during high temperature deformation in aluminium alloys. In this context, the grain size increases when the temperature increases as well as when the strain rate decreases. It is then difficult to conclude on the effect of the dynamic recrystallization on the final grain size (just after welding). Indeed, Jacquin et al. (2011) have shown that the warmer welding conditions may also imply large strain rates and thus both effects of the temperature and the strain rate would compensate according to the final grain size. However the warmer welding conditions strongly promote static recrystallization during the cooling stage after welding, the duration of which increases with the maximum temperature reached during the welding operation. The trend observed on the grain size measurement in the welded area can thus be linked with the post-dynamic mechanisms (i.e. static recrystallization after welding)).

It was decided to make a focus on 2 process conditions and to detail the effects on metallurgical evolution. Because of their great difference in morphology, material mixing, and microstructural evolution (grain size, de- 


\begin{tabular}{lccc}
\hline Sample & R ratio $\left({\left.\mathrm{mm} \cdot \mathrm{rev}^{-1}\right)}^{-}\right.$ & Average grain size $(\mu \mathrm{m})$ & Measured peak temperature $\left({ }^{\circ} \mathrm{C}\right)$ \\
\hline BW7 & 0.15 & 27,98 & 280 \\
BW4 & 0.2 & 20,85 & 266 \\
BW1 & 0.3 & 9,63 & 243 \\
BW8 & 0.35 & 21,01 & 237 \\
BW5 & 0.47 & 15,67 & 218 \\
BW9 & 0.55 & 19,81 & 173 \\
BW2 & 0.7 & 7,69 & 186 \\
BW6 & 0.73 & 10,05 & 161 \\
BW3 & 1.1 & 8,84 & 156 \\
\hline
\end{tabular}

Table 4: Comparison of AA6060 grain size inside the nugget and measured peak temperatures at $12 \mathrm{~mm}$ from the weld line sorted by ascending order of the $\mathrm{R}$ ratio.

formation) the coldest (BW3) and warmest (BW7) conditions were chosen.

Global cross section of both welds came along with zooms of the various microstructures in Fig. 9 and Fig. 10. For each process condition the ends of the welded samples are composed with base materials without any microstructural changes: the weld temperatures are low enough not to structurally modify the materials. This assumption is confirmed by the temperature measurements done in the vicinity of the joint which never exceed a quick peak of $290^{\circ} \mathrm{C}$ at $12 \mathrm{~mm}$ from the weld line (see Table 3).

A micrograph of the BW3 condition is shown in Fig. 9. Detail (I) displays severely deformed grains in the transition zone between base material (AA7020) and nugget. Through TMAZ and HAZ in AS, a clear and tilted nugget edge is revealed. Here a mixture of thin, elongated, and deformed grains along with small and recrystallized ones can be observed. On the other side (RS), the transition region from base material (AA6060) to the 


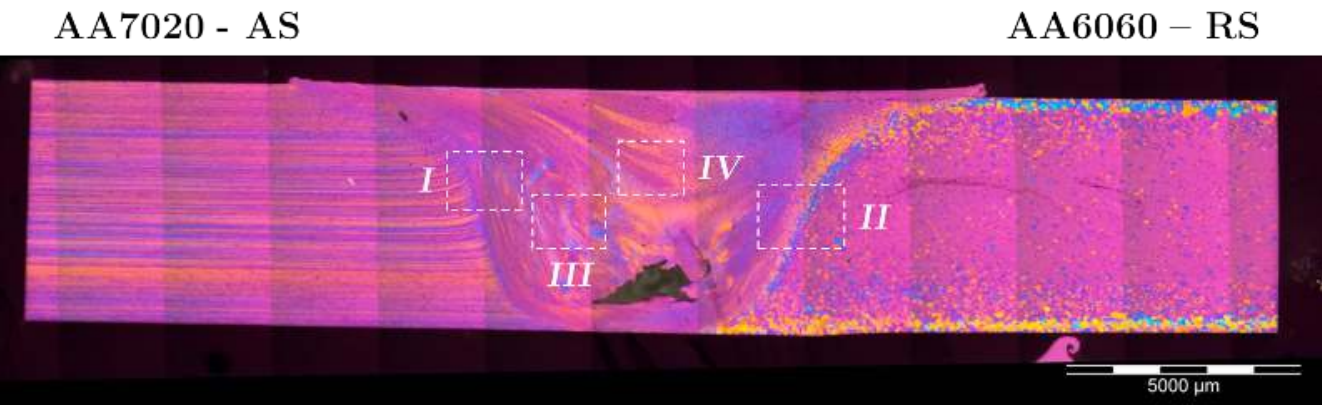

(a)
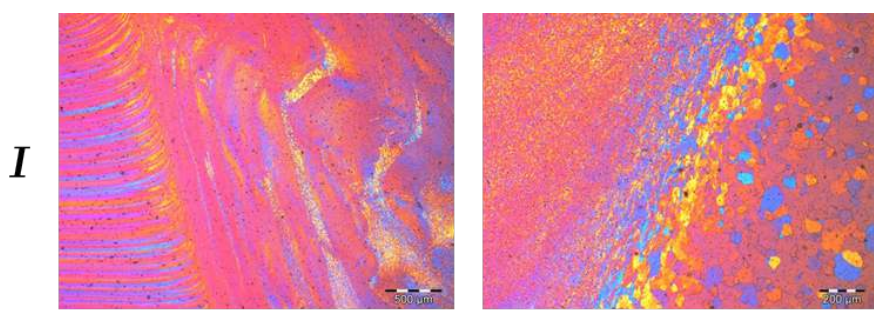

II
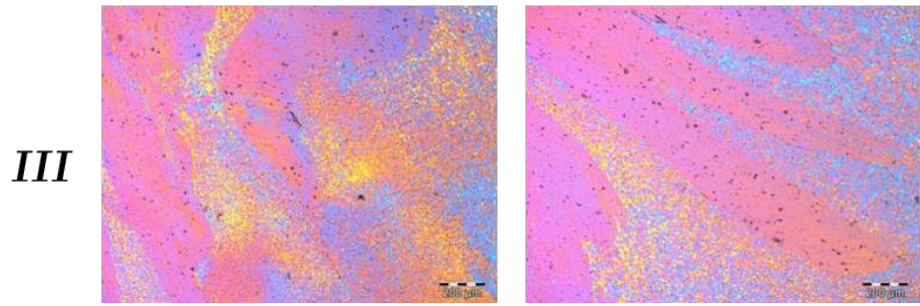

IV

(b)

Figure 9: (a) Optical micrograph of cross-section of BW3; (b) details of cross-weld: ITransition between TMAZ and nugget on AA7020 side, II-Transition between TMAZ and nugget on AA6060 side, III \& IV-Banded structure of dissimilar nugget.

nugget through TMAZ-HAZ is shown in zoom (II). Due to the microstructural features of AA6060 and the asymmetrical flow from AS to RS, the deformation in this area is less significant. Details (III) and (IV) show the banded structure in the nugget with large layers and chaotic mixing of each material. Very fine and equiaxed grains are present, exhibiting the smaller grain size of AA7020 relative to AA6060. As for the BW3 condition, detail 


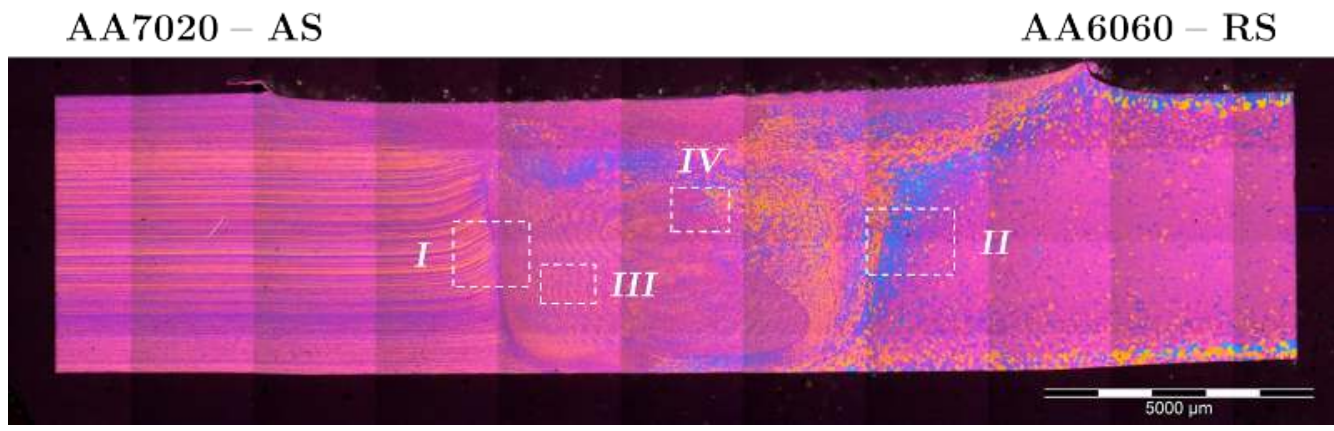

(a)
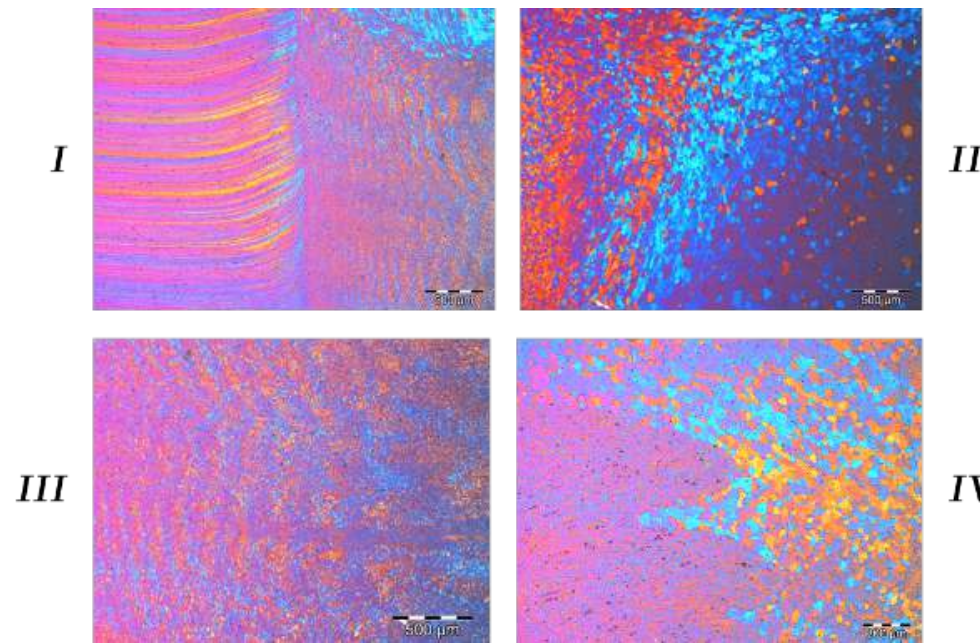

(b)

Figure 10: (a) Optical micrograph of cross-section of BW7; (b) details of cross-weld: I-Transition between TMAZ and nugget on AA7020 side, II-Transition between TMAZ and nugget on AA6060 side, III-Banded structure in the nugget on AA7020 side, IV-Both side of dissimilar nugget.

(I) of Fig. 10 also showed severely deformed grains in TMAZ-HAZ in AS. In this case, the nugget edge is identified with a sharper and vertical direction. Similar observations are done concerning recrystallization and grains deformation intensity. On the AA7020 side of the nugget (III) a banded 
structure or onion-rings can be observed. It is a sequence of thin bands having different preferred crystallographic orientations, as detailed in Robe et al. (2015) works, and generated by the process. Macrographs have revealed that the nugget is divided into a kind of tip-border shape drawing the separation between the two materials. The tool geometry could have significant effects on this interface due to the taper angle or the presence of a thread. Detail (IV) shows both materials inside the nugget which also exhibit the same grain size variation as for BW3.

\subsubsection{Reversing the material position}

In case of dissimilar welding, the question of the material position is very important and can have strong effects on the metallurgical and mechanical behaviours of the weld. The stress and strain fields are not symmetrical trough the joint, the temperature variation and localized behaviour could trigger erratic reactions. Some tests were done and revealed that depending on the process parameters, the weld cannot be performed sometimes. While for the BW3 configuration, the only correct position is the one placing AA7020-T651 on AS, the BW7 configuration (2000 rev.min ${ }^{-1}$ - 300 mm. $\mathrm{min}^{-1}$ ) provides a compact and sound weld for both material positions (see Fig. 11).

In this configuration, the AA6060-T6 (AS) seems to be predominantly present in the weld and the typical S-shape cannot be clearly identified, the interface between both materials being more disturbed. Banded structures like onion-rings are also formed inside the nugget on the AA6060-T6 side. 


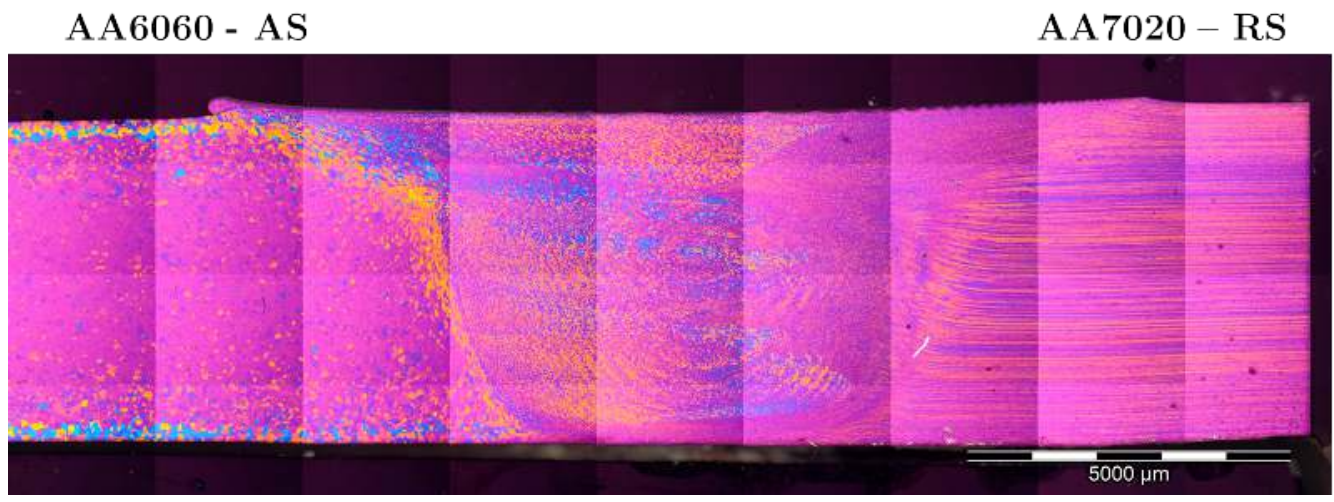

Figure 11: Optical micrographs of inverse BW7 condition.

\subsection{Mechanical characterization}

\subsubsection{Tensile properties}

Tensile properties of the base metal and dissimilar joints welded by FSW are reported in Tables 5 and 6. AA6060-T6 is an extruded profile welded parallel to the extrusion direction (ED) while AA7020-T651 sheets have their rolling direction (RD) perpendicular to the welding direction. Both directions were tested through tensile tests. Depending on the loading direction, AA7020-T651 shows a difference for UTS and elongation terms. AA6060-T6 shows elongation in the transverse direction half of the elongation in the extrusion direction. However it is important to highlight that the difference in mechanical properties of AA7020-T651 and AA6060-T6: comparing RD and TD, AA6060 is 55\% of AA7020 UTS and RP0.2, and $65 \%$ of AA7020 elongation. On Fig. $12 \mathrm{a}$ and $12 \mathrm{~b}$ the fracture appearances of both base materials are shown. One can see that both base materials have not the same fracture behavior. Indeed AA7020-T651 presents a typical $45^{\circ}$ shear direction, while AA6060-T6 has a rough fracture, with more 
2D striction than AA7020-T651.

\begin{tabular}{lcccc}
\hline Material & & RP0.2 (MPa) & UTS (MPa) & Elongation (\%) \\
\hline AA7020-T651 & (RD) & 375 & 424 & 10.6 \\
& $(\mathrm{TD})$ & 362 & 408 & 15.9 \\
AA6060-T6 & $(\mathrm{ED})$ & 206 & 233 & 14.9 \\
& $(\mathrm{TD})$ & 206 & 230 & 6.9 \\
\hline
\end{tabular}

Table 5: Room temperature tensile properties of both base metals.

For a dissimilar welding, the joint efficiency (ratio $U T S_{\text {Joint }} / U T S_{B M}$ ) could be calculated based on the weakest material (i.e. AA6060-T6 UTS $230 \mathrm{MPa})$. It is important to note that the worst efficiency reached in all conditions is $56 \%$ for RP $0.2,73 \%$ for the UTS, and $30 \%$ for the elongation (see Table 6). The elongation terms seems to be the most sensitive propertie to the welding process. In order to compare those results to a traditional fusion joining, tensile tests were performed on MIG butt joined sheets too. The welding was made by an experimented worker. For example, the best UTS-efficiency result in MIG welding is $66 \%$. It demonstrates that the FSW permits to keep a larger number of base material characteristics than fusion welding, especially MIG. For dissimilar joints, there is also a difference between joint and $\mathrm{BM}$ in terms of ductility. Joint elongations are equal of AA6060-T6 elongation in the transverse direction (the one which is tested during the tensile test), but around $70 \%$ of AA7020-T651 elongation (rolling direction).

The maximum yield strength and one of the highest tensile strength were obtained for the "cold weld" (BW3) but also the lowest elongation. It 22 
is to be noted that some void defects were detected for this configuration and could alter the mechanical behavior. But the results repeatability on several welded plates is good. In contrast, the lowest yield and tensile strength associated with the better elongation have been obtained for a "hot weld" (BW7). Inversion of materials position in the "hot weld" condition seems to give very similar results to the original configuration. Based on the tensile properties, there is no real interest to change the position of each material.

It is shown in Fig, 12 that in all cases, fracture occurred on RS (i.e. AA6060-T6 side, the weakest material) of the joint and more specifically on the transition zone between nugget and base material (only one representative picture is shown).

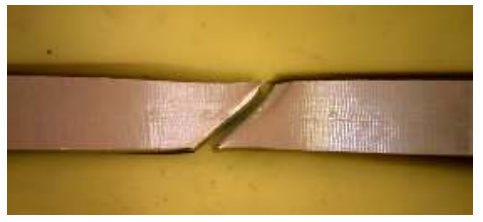

(a)

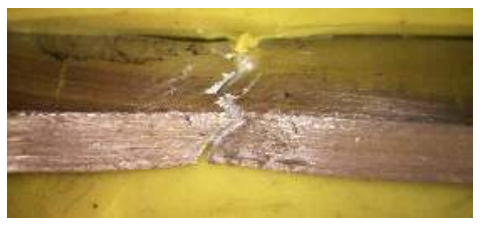

(b)

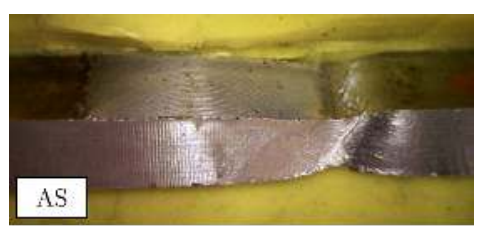

(c)

Figure 12: Fractography results : (a) Fractography picture of AA7020-T651 (RD), (b) Fractography picture of AA6060-T6 (TD), (c) Fractography picture of BW5 condition (representative of every joints fracture). 


\begin{tabular}{|c|c|c|c|c|c|c|c|}
\hline Samples & Type & $\begin{array}{l}\mathrm{RP} 0.2 \\
(M P a)\end{array}$ & $\begin{array}{c}\mathrm{UTS} \\
(M P a)\end{array}$ & $\begin{array}{c}\text { Elongation } \\
\text { (\%) }\end{array}$ & $\begin{array}{c}\text { Eff. RP0.2 } \\
(\%)\end{array}$ & $\begin{array}{c}\text { Eff. UTS } \\
(\%)\end{array}$ & $\begin{array}{c}\text { Eff. A\% } \\
(\%)\end{array}$ \\
\hline \multirow[t]{2}{*}{ BW1 } & Average & 125 & 170 & 5.6 & \multirow{2}{*}{61} & \multirow{2}{*}{74} & \multirow{2}{*}{41} \\
\hline & St. Deviation & 3.2 & 4.9 & 1.7 & & & \\
\hline \multirow[t]{2}{*}{ BW2 } & Average & 136 & 178 & 4.8 & \multirow{2}{*}{66} & \multirow{2}{*}{77} & \multirow{2}{*}{36} \\
\hline & St. Deviation & 3.8 & 4.4 & 2.1 & & & \\
\hline \multirow[t]{2}{*}{ BW3 } & Average & 145 & 183 & 4.7 & \multirow{2}{*}{71} & \multirow{2}{*}{78} & \multirow{2}{*}{30} \\
\hline & St. Deviation & 2.9 & 4.9 & 1.3 & & & \\
\hline \multirow[t]{2}{*}{ BW4 } & Average & 117 & 175 & 6.7 & \multirow{2}{*}{57} & \multirow{2}{*}{76} & \multirow{2}{*}{50} \\
\hline & St. Deviation & 4.2 & 2.1 & 1.0 & & & \\
\hline \multirow[t]{2}{*}{ BW5 } & Average & 125 & 179 & 6.7 & \multirow{2}{*}{61} & \multirow{2}{*}{78} & \multirow{2}{*}{50} \\
\hline & St. Deviation & 3.5 & 0.6 & 0.9 & & & \\
\hline \multirow[t]{2}{*}{ BW6 } & Average & 132 & 181 & 6.4 & \multirow{2}{*}{64} & \multirow{2}{*}{79} & \multirow{2}{*}{47} \\
\hline & St. Deviation & 5.0 & 0.0 & 1.0 & & & \\
\hline \multirow[t]{2}{*}{ BW7 } & Average & 116 & 167 & 6.3 & \multirow{2}{*}{56} & \multirow{2}{*}{73} & \multirow{2}{*}{47} \\
\hline & St. Deviation & 5.5 & 7.8 & 1.3 & & & \\
\hline \multirow[t]{2}{*}{ BW8 } & Average & 124 & 173 & 5.6 & \multirow{2}{*}{60} & \multirow{2}{*}{75} & \multirow{2}{*}{41} \\
\hline & St. Deviation & 4.2 & 6.4 & 1.5 & & & \\
\hline \multirow[t]{2}{*}{ BW9 } & Average & 134 & 182 & 6.1 & \multirow{2}{*}{65} & \multirow{2}{*}{79} & 45 \\
\hline & St. Deviation & 1.2 & 2.3 & 0.9 & & & \\
\hline Inverse BW7 & Average & 118 & 161 & 5.4 & 57 & 70 & 10 \\
\hline & St. Deviation & 4.9 & 0.6 & 0.2 & 1 & 10 & 70 \\
\hline
\end{tabular}

Table 6: Room temperature tensile properties of the dissimilar welds 7020-T651 / 6060T6. Average value represents average of test results of three samples.

\subsubsection{Microhardness}

Like macrographs, microhardness maps are classified following the process parameters and the $\mathrm{R}$ ratio on Fig. 13. The hardness of both base materials are respectively $130 \mathrm{HV}_{0.1}$ for AA7020-T651 and $85 \mathrm{HV}_{0.1}$ for AA6060-T6. Generally in FSW, hardness profiles of precipitation hardening alloys follow the typical "W-shape" and reach a minimum in the heat 
affected zone (HAZ). In the case of dissimilar welding, the profiles are assumed to be a combination of both material hardness profiles as reported by many authors such as Murr (2010), Simar et al. (2010), and Robe et al. (2015). The same conclusion can be made in this study. It is very interesting to compare microhardness and microstructure results in the $\mathrm{CW}$ section, because all microhardness areas highlighted in the maps match with the typical FSW zones revealed on the macrographs. It is possible to distinguish the materials interface, the nugget, HAZ and TMAZ. We can observe the great range of microhardness (from 40 to 130 HV0.1) and the sharp evolution of measurements along the cross section of the weld.

It can be noted that the HAZ width decreases when $\mathrm{R}$ ratio gets higher. With a high $\mathrm{R}$ ratio, the heat input is low enough to locate the metallurgical transformation and softening only in a narrow area around the pin. On AS the softening area ended approximatively $10 \mathrm{~mm}$ from the weld line for $\mathrm{R}=1.1$ (cold weld) and more than $15 \mathrm{~mm}$ for $\mathrm{R}=0.15$ (hot weld). The same trend can be observed on RS. This allows us to link the microhardness behavior and the tensile results. With any parameters, the fracture was located on RS and seems to match with the minimum hardness area as expected with various literature works.

Fig. 14 shows microhardness evolution of both BW7 and inverse BW7 configurations. One can see that the transition from the material positioned in $\mathrm{AS}$ to the material in RS is smoother for the inverse BW7 configuration. A sharp drop is present in the case of placing AA7020 in AS, but when AA6060 is placed in AS, the low value of hardness increases slowly to reach a maximum at the boundary of the joint in AA7020 side. If microhardness and fracture location are connected, one can note that the fracture occurred 
once more is the area of the lowest hardness (about $10 \mathrm{~mm}$ from the weld line in $\mathrm{AS})$.

\section{Conclusions}

The goal of this paper was to demonstrate the feasibility of FSW to join AA7020-T651 and AA6060-T6. Thanks to several investigations on experimental tests, microstructure, mechanical behavior and microhardness, we can provide satisfactory results.

- Friction stir welds of AA7020-T651 with AA6060-T6 can be produced with satisfactory joint efficiency $(62 \%+/-4.6-76 \%+/-2.9-43 \%$ +/-6.3 compared to AA6060 UTS) whatever the positioning of the base materials and despite some defects.

- We are able to weld a dissimilar set up under standard industrial conditions, i.e. the process parameters make it possible to challenge other conventional welding processes.

- The temperature measurements permit to say that the steady state condition is reached rather quickly with few temperature differences for each material.

- The process parameters have an influence on material mixing, weld integrity and mechanical behavior. When the advancing speed increases, the interface between both base metals becomes disrupted on the cross weld direction but it becomes cyclical on the welding direction. High welding velocities or cold conditions also enhanced grain refinement in AA6060-T6 nugget.

- The links between the microhardness and the fracture during tensile tests are shown. Whatever the positioning of the base materials, the 
fracture is always located on the minimum hardness area.

\section{Acknowledgements}

Landry Giraud, Hugo Robe, Christophe Claudin, and Eric Feulvarch acknowledge the French government defense agency, Direction Générale de l'Armement (DGA), for providing financial support of the RAPID - DISTIR project headed by TRA-C industrie.

\section{References}

Carlone, P., Astarita, A., Palazzo, G. S., Paradiso, V., Squillace, A., Feb. 2015. Microstructural aspects in Al-Cu dissimilar joining by FSW. The International Journal of Advanced Manufacturing Technology 79 (5-8), 1109-1116.

URL http://link . springer .com/article/10.1007/s00170-015-6874-z

Carlone, P., Palazzo, G., Jan. 2015. Characterization of TIG and FSW weldings in cast ZE41A magnesium alloy. Journal of Materials Processing Technology 215 (0), 87-94.

URL http://www.sciencedirect.com/science/article/pii/S0924013614002854

Cavaliere, P., Santis, A. D., Panella, F., Squillace, A., 2009. Effect of welding parameters on mechanical and microstructural properties of dissimilar AA6082-AA2024 joints produced by friction stir welding. Materials \& Design 30 (3), $609-616$.

URL http://www. sciencedirect .com/science/article/pii/S0261306908002240

da Silva, A., Arruti, E., Janeiro, G., Aldanondo, E., Alvarez, P., Echeverria, A., Apr. 2011. Material flow and mechanical behaviour of dissimilar AA2024-T3 and AA7075T6 aluminium alloys friction stir welds. Materials \& Design 32 (4), 2021-2027.

URL http://www.sciencedirect.com/science/article/pii/S0261306910006850

Dilip, J., Koilraj, M., Sundareswaran, V., Janaki Ram, G., Koteswara Rao, S., Aug. 2010. Microstructural characterization of dissimilar friction stir welds between AA2219 and AA5083. Transactions of the Indian Institute of Metals 63 (4), 757-764.

URL http://dx.doi .org/10.1007/s12666-010-0116-8 
Feulvarch, E., Robin, V., Bergheau, J. M., Apr. 2011. Thermometallurgical and mechanical modelling of welding -" application to multipass dissimilar metal girth welds. Science and Technology of Welding and Joining 16 (3), 221-231.

URL http://www . maneyonline.com/doi/abs/10.1179/1362171811Y.0000000008

Genevois, C., Deschamps, A., Denquin, A., Doisneau-cottignies, B., May 2005. Quantitative investigation of precipitation and mechanical behaviour for AA2024 friction stir welds. Acta Materialia 53 (8), 2447-2458.

URL http://www.sciencedirect.com/science/article/pii/S1359645405000832

Gourdet, S., Montheillet, F., May 2003. A model of continuous dynamic recrystallization. Acta Materialia 51 (9), 2685-2699.

URL http://www . sciencedirect.com/science/article/pii/S1359645403000788

Gratecap, F., Girard, M., Marya, S., Racineux, G., Jun. 2012. Exploring material flow in friction stir welding: Tool eccentricity and formation of banded structures. International Journal of Material Forming 5 (2), 99-107.

URL http: //link .springer .com/10.1007/s12289-010-1008-5

Hamilton, C., Dymek, S., Blicharski, M., Sep. 2008. A model of material flow during friction stir welding. Materials Characterization 59 (9), 1206-1214.

URL http://www . sciencedirect.com/science/article/pii/S1044580307003580

Ilangovan, M., Boopathy, S. R., Balasubramanian, V., 2015. Microstructure and tensile properties of friction stir welded dissimilar AA6061-AA5086 aluminium alloy joints. Transactions of Nonferrous Metals Society of China 25 (4), 1080 - 1090.

URL http://www.sciencedirect.com/science/article/pii/S1003632615637013

Izadi, H., Fallu, J., Abdel-Gwad, A., Liyanage, T., Gerlich, A. P., May 2013. Analysis of tool geometry in dissimilar Al alloy friction stir welds using optical microscopy and serial sectioning. Science and Technology of Welding and Joining 18 (4), 307-313.

URL http://www . maneyonline.com/doi/abs/10.1179/1362171813Y.0000000107

Jacquin, D., de Meester, B., Simar, A., Deloison, D., Montheillet, F., Desrayaud, C., Jan. 2011. A simple Eulerian thermomechanical modeling of friction stir welding. Journal of Materials Processing Technology 211 (1), 57-65.

URL http://www . sciencedirect.com/science/article/pii/S092401361000258X

Jonckheere, C., de Meester, B., Denquin, A., Simar, A., 2013. Torque, temperature and 
hardening precipitation evolution in dissimilar friction stir welds between 6061-T6 and 2014-T6 aluminum alloys. Journal of Materials Processing Technology 213 (6), 826 837.

URL http://www.sciencedirect.com/science/article/pii/S0924013613000083

Khodir, S. A., Shibayanagi, T., 2007. Dissimilar friction stir welded joints between 2024-

T3 aluminum alloy and AZ31 magnesium alloy. Materials transactions 48 (9), 25012505 .

URL http://jlc.jst.go.jp/DN/JALC/00298728648?from=Google

Lorrain, O., Favier, V., Zahrouni, H., Lawrjaniec, D., 2010. Understanding the material flow path of friction stir welding process using unthreaded tools. Journal of Materials Processing Technology 210 (4), 603 - 609.

URL http://www.sciencedirect.com/science/article/pii/S092401360900404X

Luijendijk, T., Jun. 2000. Welding of dissimilar aluminium alloys. Journal of Materials Processing Technology 103 (1), 29-35.

URL http://www.sciencedirect.com/science/article/pii/S0924013600004155

Mofid, M. A., Abdollah-zadeh, A., Gür, C. H., Mar. 2014. Investigating the formation of intermetallic compounds during friction stir welding of magnesium alloy to aluminum alloy in air and under liquid nitrogen. The International Journal of Advanced Manufacturing Technology 71 (5-8), 1493-1499.

URL http://link.springer .com/10.1007/s00170-013-5565-x

Mubiayi, M. P., Akinlabi, E. T., May 2013. Friction stir welding of dissimilar materials: An overview. International Journal of Mechanical, Aerospace, Industrial, Mechatronic and Manufacturing Engineering 7, 232-238.

URL http: //waset .org/publications/14488

Muñoz, A. C., Rückert, G., Huneau, B., Sauvage, X., Marya, S., Feb. 2008. Comparison of TIG welded and friction stir welded Al-4.5Mg-0.26Sc alloy. Journal of Materials Processing Technology 197 (1-3), 337-343.

URL http://www . sciencedirect.com/science/article/pii/S0924013607006280

Murr, L. E., Nov. 2010. A review of FSW research on dissimilar metal and alloy systems. Journal of Materials Engineering and Performance 19 (8), 1071-1089.

URL http://link.springer .com/10.1007/s11665-010-9598-0 
Nandan, R., Roy, G. G., Lienert, T. J., DebRoy, T., Sep. 2006. Numerical modelling of $3 \mathrm{D}$ plastic flow and heat transfer during friction stir welding of stainless steel. Science and Technology of Welding and Joining 11 (5), 526-537.

URL http://www . maneyonline.com/doi/abs/10.1179/174329306X107692

Park, S.-K., Hong, S.-T., Park, J.-H., Park, K.-Y., Kwon, Y.-J., Son, H.-J., May 2010. Effect of material locations on properties of friction stir welding joints of dissimilar aluminium alloys. Science and Technology of Welding and Joining 15 (4), 331-336.

URL http://www.maneyonline.com/doi/abs/10.1179/ $136217110 X 12714217309696$

Robe, H., Zedan, Y., Chen, J., Feulvarch, E., Bocher, P., Oct. 2015. Microstructural and mechanical characterization of a dissimilar friction stir welded butt joint made of AA2024-T3 and AA2198-T3. Materials Characterization.

URL http://linkinghub.elsevier.com/retrieve/pii/S1044580315300322

Simar, A., Jonckheere, C., Deplus, K., Pardoen, T., de Meester, B., Apr. 2010. Comparing similar and dissimilar friction stir welds of 2017-6005a aluminium alloys. Science and Technology of Welding and Joining 15 (3), 254-259.

URL

http://www.maneyonline.com/doi/abs/10.1179/

$136217110 X 12665048207737$

Thomas, W., Murch, M., Nicholas, E., Temple-Smith, P., Needham, J., Dawes, C., May 17 1995. Improvements relating to friction welding. EP Patent App. EP19,940,120,385.

URL https://www.google.fr/patents/EP0653265A2?cl=en

Tongne, A., Jahazi, M., Feulvarch, E., Desrayaud, C., Jul. 2015. Banded structures in friction stir welded al alloys. Journal of Materials Processing Technology 221 (0), 269 278.

URL http://www.sciencedirect.com/science/article/pii/S0924013615000631

$\mathrm{Xu}$, S., Deng, X., Apr. 2008. A study of texture patterns in friction stir welds. Acta Materialia 56 (6), 1326-1341.

URL http://www . sciencedirect.com/science/article/pii/S1359645407007938

Zhao, J., Jiang, F., Jian, H., Wen, K., Jiang, L., Chen, X., Jan. 2010. Comparative investigation of tungsten inert gas and friction stir welding characteristics of $\mathrm{Al}-\mathrm{Mg}$ - 
Sc alloy plates. Materials \& Design 31 (1), 306-311.

URL http://linkinghub.elsevier.com/retrieve/pii/S026130690900291X 


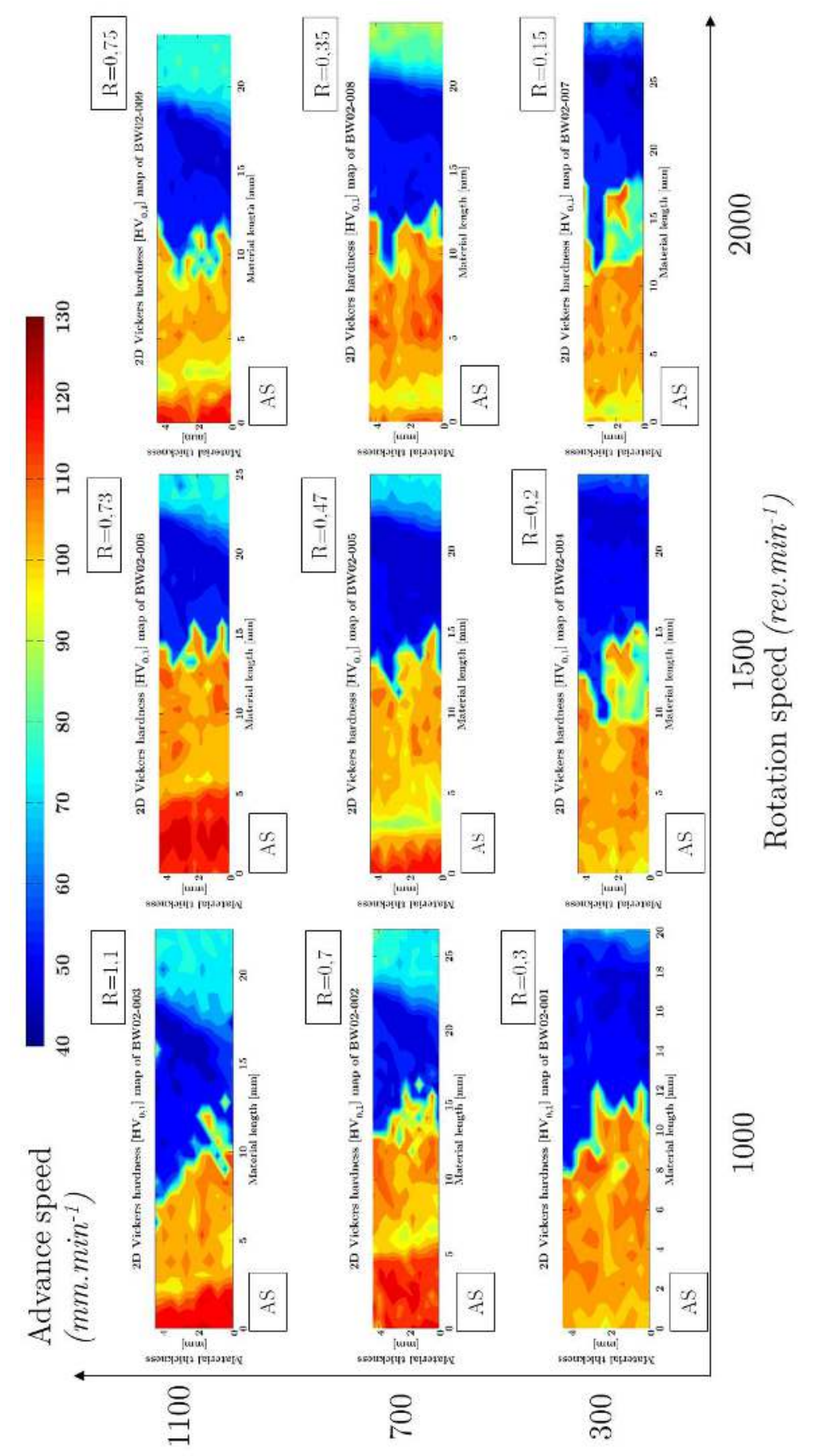

Figure 13: Microhardness maps matrix of cross weld sections. 


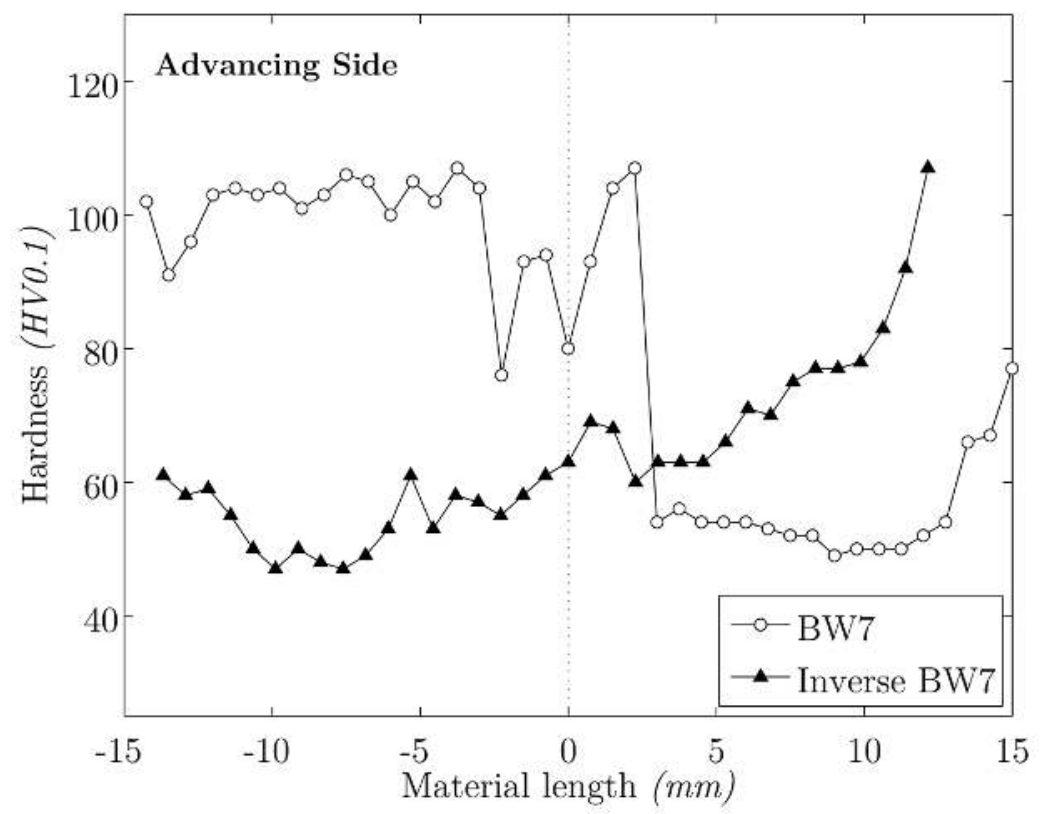

Figure 14: Microhardness profiles at mid-thickness of BW7 and inverse BW7 conditions. 